\title{
BREVE DESCRIPCIÓN DE LA COMUNIDAD CUCAPÁ DEL RÍO HARDY, BAJA CALIFORNIA
}

\author{
Por \\ Julia Bendímez Patterson*
}

\begin{abstract}
RESUMEN
En este artículo se hace una breve descripción de la situación actual que enfrenta la comunidad cucapá El Mayor, para esto se toman en consideración algunos acontecimientos históricos, el cambio de su entorno natural y su modo de procurarse el sustento. El propósito es ilustrar el difícil reto que enfrenta en el futuro inmediato este grupo indígena ancestral.
\end{abstract}

\begin{abstract}
In this article a brief description is made about the present state of the cucapa people from EI Mayor. In order to accomplish this some historic events, accounts about their way of making a living and the transformation of their natural environment are taken into consideration. The purpose is to ilustrate the difficult challange that this ancestral group faces in the near future.
\end{abstract}

En diversas fuentes bibliográficas, documentos históricos y versiones orales se describe a la comunidad cucapá cuyos ancestros vivieron en la región del sur del valle de Mexicali hasta la boca del río Colorado, un tiempo considerable antes de la llegada de gente de origen no-indígena.

* Investigadora del Instituto de Investigaciones Sociales de la Universidad Autónoma de Baja California y delegada regional del Instituto Nacional de Antropología e Historia en Baja California (INAH). 
Todas estas fuentes nos ayudan a formarnos una vision de su devenir histórico, antecedentes prehispánicos, cosmogonía, costumbres y economía en diversos momentos de su existencia. En este trabajo intentamos volver la atención a varios de estos aspectos y describir la manera en la que hoy se encuentra esta comunidad ancestral. Con ello nos daremos una idea de los retos que confrontan en el futuro inmediato.

Esta gente es alta, bien formada, y sin gordura, de su nariz perforada, cuelgan pendientes, otros cuelgan conchas, sus orejas también están perforadas en muchos lugares y cuelgan cuentas (rosarios), y conchas. Todos, jóvenes y viejos usan una cuerda alrededor de la cintura. La cuerda está hecha de varios colores, en medio han atado un montón de plumas, que caen por su parte trasera como una cola...Sus mujeres andan desnudas y usan un manojo de plumas en frente y por detrás, pintados y pegados unos a otros (Hernando de Alarcón en Williams, 1975:26).

Los cucapá son los descendientes de un pueblo indígena que desarrollo una forma de vivir que les permitio dominar, durante por lo menos 1500 años, la región del extremo noreste de lo que hoy en día es Baja California (ver figura 1).

El vocablo cucapá posiblemente proviene de kush, alto o largo y del apá que significa hombre (Trujillo, 1983:6). También es usual el vocablo chapai, utilizado por el propio pueblo cucapá para autodenominarse.

\section{LOCALIZACIÓN}

Existen tres comunidades cucapá: una en Somerton, California, E.U., otra en Pozas de Arvizu en el estado de Sonora, y la que se encuentra en Baja California en el municipio de Mexicali. Este núcleo de población cucapá, denominado Cucapá El Mayor, actualmente está ubicado entre la rivera del río Colorado y las estribaciones de la sierra Cucapá en la porción sureste del valle de Mexicali, Baja California, dentro de la delegación municipal Carranza. El asentamiento se encuentra en una de las afluencias del río Colorado llamado río Hardy y en las faldas del Cerro El Mayor, en el km 57 junto a la carretera federal núm. 5 de Mexicali a San Felipe. Hay también cucapá viviendo en la ciudad de Mexicali y en algunos ejidos tales como el denominado Cucapá Indígena.

Las coordenadas de la comunidad son $32^{\circ} 15^{\prime}$ de latitud Norte y $115^{\circ} 20^{\prime}$ longitud oeste. Esta zona está compuesta por suelos desérticos pedregosos no aptos para el cultivo; no obstante, al norte las tierras de este pueblo indígena colindan con campos agrícolas del valle de Mexicali. En 


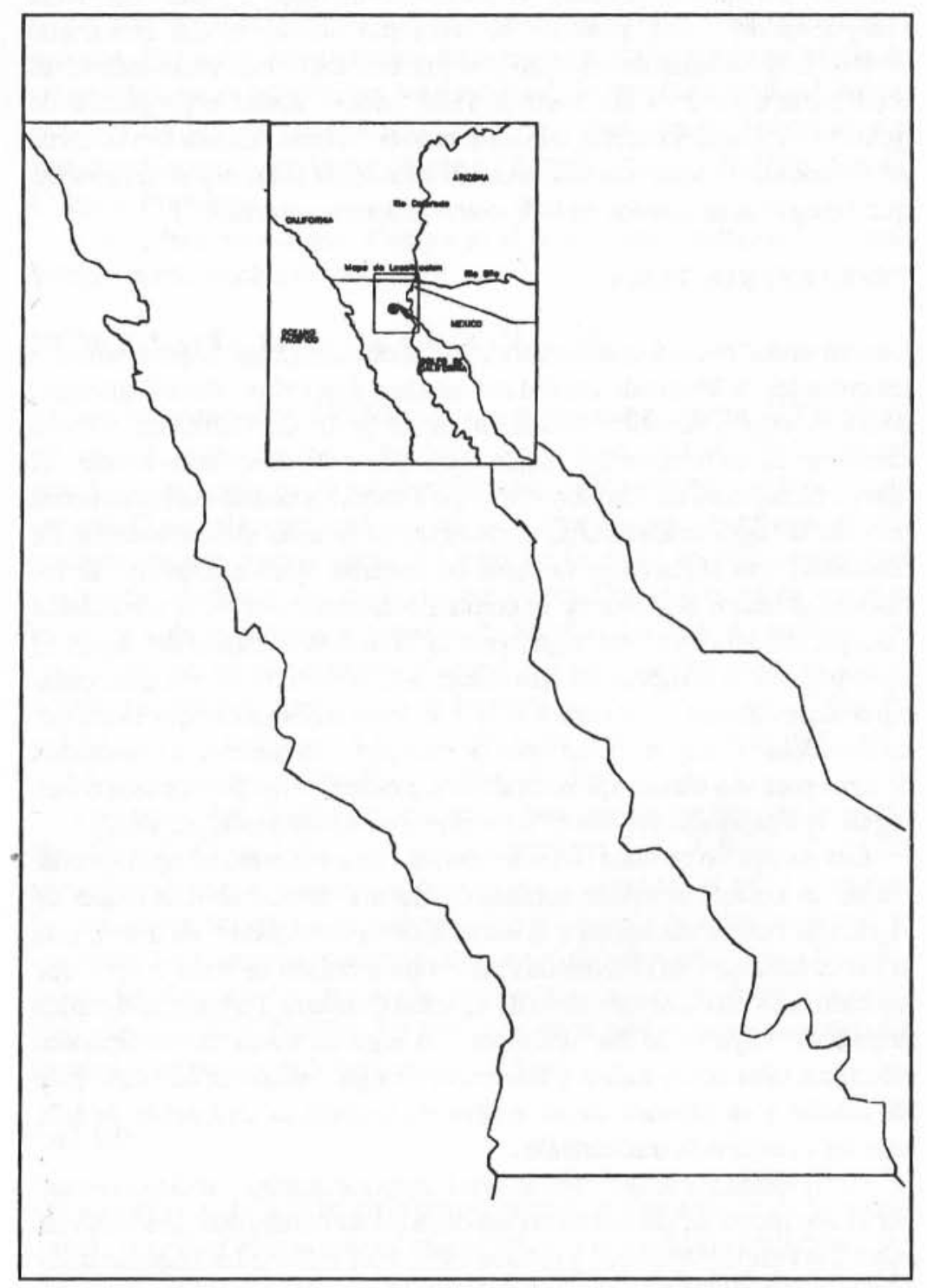

Figura 1. Ubicación de la comunidad cucapá. 
términos urbanos el poblado se encuentra dividido en una cuadrícula compuesta de varias avenidas de terracería donde se han construido viviendas de bloques de cemento y de madera. Estos materiales empiezan a utilizarse a partir de la década de 1980, cuando iniciaron programas de gobiemo orientados hacia el mejoramiento de sus condiciones de vivienda. Anteriormente construían sus casas de cachanilla (Pluchea sericea) a las que agregaban aplanados de lodo como aislantes naturales.

\section{INFRAESTRUCTURA}

La comunidad cucapá se encuentra sobre la carretera núm. 5, que comunica las ciudades de Mexicali, capital del estado y San Felipe, Baja Califomia, puerto y centro turístico localizado en el golfo de California. Otros caminos son de terracería y llegan a campos turísticos, como lo son: el campo Mosqueda, La Carpa, y el campo Tres B. La comunidad cuenta con servicio de agua domiciliaria, a través de un sistema hidroneumático de rebombeo con almacenaje de agua en cisterna, que se abastece de los canales aledaños del área de la colonia Mariana cerca de la comunidad Cucapá, servicio que es sufragado por la Comisión Nacional del Agua. El agua potable la compran en garrafones que se venden en algunas casas particulares dentro de la comunidad o de los distribuidores que la cargan en camiones "del agua". Camiones de pipa también surten a la comunidad de agua para uso diario, aproximadamente cuatro veces por semana o más según la temporada del año (Víctor Navarro, información personal).

Los cucapá no cuentan con teléfonos ni con un sistema telegráfico aún. Existe un correo, instalado rudimentariamente dentro de una caseta de vigilancia que se encuentra a la entrada de la comunidad, en donde está también instalado un sistema de radio comunicación de onda corta y que los comunica con la oficina de la delegación Carranza. La energía eléctrica llega a la mayoría de las viviendas. En algunos casos tienen aparatos eléctricos tales como radios y televisores. El gas butano es utilizado para las estufas y en algunos casos se observa también la utilización de leña para las estufas más tradicionales.

Pocas familias cucapá cuentan con transporte automovilístico personal por lo que recurren, cuando es necesario, a los autobuses que tienen su ruta entre San Felipe y Mexicali y los que vienen del valle de La Trinidad hacia Mexicali. La Promotora del Estado proporciona servicio de transporte a estudiantes de secundaria cobrandoles una cuota semestral de $\$ 175.00$ m.n., con derecho a credenciales para trasladarse a los distintos centros de estudio aledaños a la comunidad, tales como los que existen en los ejidos Durango, Nuevo León y en la propia ciudad de Mexicali. 
Los cucapá tienen un jardín de niños y una escuela primaria en donde se imparte una educación monolingüe. Otros servicios con los que cuentan son una clínica del Seguro Social, una caseta de vigilancia y una tienda de CONASUPO que es operada por particulares de la propia comunidad. Existe también un museo comunitario que forma parte de un programa del Instituto Nacional de Antropología e Historia (INAH) y la Dirección de Culturas Populares.

Una iglesia protestante aleluya es el único centro religioso que prevalece en este núcleo de población.

\section{DEMOGRAFÍA, LENGUA Y EDUCACIÓN}

En la comunidad cucapá El Mayor existen aproximadamente 212 habitantes cucapá, según un censo realizado por el IMSS en 1995. No existe un estudio actualizado que explique el f́ndice de población que habla la lengua cucapá. El actual comisariado ejidal, Sr. Víctor Navarro opinб que aproximadamente una tercera parte del total de la gente en esta comunidad "entiende" el idioma nativo. La lengua original casi no se habla, excepto en el caso de los ancianos mayores de 60 años que son, en realidad, un porcentaje mínimo de la población total; por tal motivo es evidente que el idioma cucapá está prácticamente desplazado por el castellano. También existen algunos hablantes del inglés debido a las relaciones de parentesco que hay con la comunidad de Somerton, Arizona.

La comunidad de El Mayor Cucapá únicamente cuenta con el jardín de niños Teodosa Saiz y la escuela primaria Lic. Alfonso Caso. La secundaria a la que acuden los jóvenes se encuentra en el ejido Durango. La educación formal es monolingüe. En el seno de la familia cucapá se aprenden las costumbres y otros aspectos culturales tales como las artesanías locales, que han rescatado algunas mujeres como doña Inocencia González y Adela Portillo. La artesanía de chaquira es una importante fuente de ingreso para la economía familiar.

\section{SALUD}

De acuerdo con la información proporcionada por miembros de la comunidad cucapá, el último cucapá que practicaba la medicina tradicional fue don Juan García Aldama, quien murió en 1991 cuando contaba con más de cien años. Actualmente la gente se aplica remedios caseros que contienen elementos de la medicina tradicional, aún recordada, y también utilizan la medicina institucional que ofrece la clínica del Instituto del Seguro Social (IMSS Solidaridad) que se encuentra en la comunidad y que 
cuenta con un médico y dos enfermeras. Es una unidad de medicina rural que tiene un primer nivel de atención, más el servicio de emergencias.

Según personal del IMSS los habitantes de la comunidad padecen comúnmente infecciones de las vías respiratorias altas, cuadros alérgicos como rinitis alérgica, dermatitis y conjuntivitis, gastroenteritis como la diarrea, intoxicaciones alimenticias y parasitosis, además de resfriados (información Juana Torres, enfermera).

Los recursos terapéuticos con los que cuenta la clínica consisten en primeros auxilios, vacunas, sueros, medicamentos alopatas, equipo quirúrgico para cirugía menor y atención de parto, equipo de nenoclisis, estuche de diagnóstico, y equipo para la toma de signos vitales.

\section{VIVIENDA}

Durante las primeras décadas de este siglo varios investigadores describen la vivienda cucapá. A partir de esta literatura podemos observar como estas sociedades construyeron sus hogares de acuerdo con sus necesidades, adaptándose sobre todo al clima y a sus actividades económicas. Autores como Gifford (1933) y Kelly (1977) explican que existieron viviendas rectangulares grandes y chicas y una cónica. Apunta Gifford que la cónica era en donde dormía la familia durante las temporadas frías. Este tipo de vivienda medía 10 pies de diámetro por 7 de altura. Las rectangulares grandes eran permanentes según Kelly y se construían en zonas elevadas cercanas a los sembradíos. La casa rectangular chica la llegaron a construir en la proximidad de los campos de arroz en la vecindad de la boca del río Colorado.

Hoy los cucapá recuerdan como hace algunas décadas construían sus casas con varillas de mezquite para la estructura de las paredes, recubriéndolas de cachanilla y emplastándolas de lodo. El techo lo construían finalmente de tule (Inocencia González, informante cucapá). A raíz de las fuertes inundaciones que ocurrieron en 1980, el gobierno del estado donó un pie de casa para cada familia. Los miembros de estos grupos familiares se encargaron de construir estas viviendas con los materiales donados, que consistieron en triplai, cemento, madera, lámina de asbesto y alambre de pollo. Es evidente que con estos materiales las viviendas perdieron considerablemente su característica térmica todo por la cultura constructiva "moderna" del momento.

En la mayoría de los casos las viviendas consisten en dos cuartos únicamente, uno que es utilizado como dormitorio y el otro para la cocina y área de recepción de visitantes. Esta distribución se repite en otras comunidades tales como las kumiai y pai pai. 
Las casas habitación tienen una toma de agua y un tablero eléctrico por domicilio. Este asentamiento humano no cuenta con un sistema de drenaje; la mayoría de los habitantes tienen letrinas y sólo en tres casos se cuenta con fosas sépticas.

\section{ANTECEDENTES HISTÓRICOS}

Las tierras aledañas al río Colorado, abundantes en recursos naturales, permitieron el surgimiento de sociedades de agricultores, pescadores, recolectores y cazadores seminómadas como los cucapá.

Otras sociedades aborígenes que habitaron a lo largo del río fueron pueblos lingüísticamente relacionados con los cucapá, tales como los mohave, quechán o yumas y los maricopa, así como otros grupos que se conocen poco etnográficamente, como los halchidoma, kavelchadom y los kwan. Por otro lado existió un pueblo en el Valle Imperial y en la región de Mexicali que también compartía rasgos culturales y lingüísticos con las etnias del río; estos últimos eran denominados kamía o diegueños del desierto (Laylander, 1993:54).

Las sociedades mencionadas líneas arriba hablaban idiomas emparentados de la familia lingüística yumana y en las que se clasifican como "yumanas rivereñas. Son producto de la evolución de lenguajes que descienden en Baja California del filum lingüístico hokano hace alrededor de 6000 años, según estudios glotocronológicos. Otras lenguas de la familia lingüística yumana que aún se hablan en el noreste en Baja Califomia son el kumiai, pai pai y el kiliwa" (Laylander, 1993:18; ver figuras 2 y 3 ).

En términos arqueológicos podemos observar que antecedieron en el territorio habitado historicamente por los cucapá y por los integrantes de la familia lingüísticamente yumana, grupos humanos que legaron un complejo arqueológico que son denominados de diversas formas: yumano, hakataya o patayan. Aparentemente, en la actualidad el término más aceptado es el hakataya. Su temporalidad se ubica en la prehistoria tardía y se calcula que podra tener una antigüedad de 1500 años. Este complejo o conjuntos de vestigios físicos contiene elementos que se reconocen etnograficamente entre los instrumentos de trabajo y otros aspectos de la cultura cucapá. En general las sociedades que habitaban la región inmediatamente antes del contacto construían viviendas ribeteadas de rocas, elaboraban figuras de grava o con piedras grandes, hacían hornos forrados de piedras para el cocimiento del agave, ponian cúmulos de rocas en ciertos puntos de sus senderos, utilizaban metates y morteros portatiles o en roca fija, elaboraban objetos de cerámica, hacían ornamentos de concha y de 
piedra, preferian puntas de proyectil desde un tamaño mediano hasta alargados, sin aleta, con base concava y vivían en pueblos pequeños con sembradíos chicos (Bendímez, 1991:23).

Los cucapá entraron en contacto en el siglo XVI con exploradores y soldados españoles que buscaban rutas estratégicas por tierra y mar para extender su mejor dominio del norte de la Nueva España. Estos viajeros intrusos se encontraron con pueblos que tenfan una estructura política y social que se basaba en lo que en la lengua vernácula se denomipa chumul. Según William Kelly (1977:11), en el siglo XIX existran cuatro bandas o chumuls: Wi Ahwil, Kwakwarsh, Mat Skrui y Hwañac (ver figura 4). Los Wi Ahwir vivían en los cerros arenosos en la zona occidental del delta del rfo Colorado. Los Kwakwarsh, vivían al sur de El Mayor Cucapá, hasta el límite de las aguas dulces del río. La banda Mat Skrui habitaba el centro y el extremo lado este y por último hacia el sur de éstos se encontraban los Hwañak. Estas entidades tenían sus propios líderes pero se encontraban sujetos a un liderazgo central, que trascendía el chumul y, en el caso de guerra, los cucapá formaban una "nación" (Bendímez 1987:18).

La primera descripción en una fuente escrita de este pueblo fue realizada por Hernando de Alarcon, quien hizo un viaje por el río Colorado en el año de 1540. Escribió que los hombres que cargaban su arco y flecha usaban taparrabos, adomaban sus caras con pintura. Las mujeres se colgaban manojos de plumas desde sus cinturas por enfrente y por detrás. En 1540 también Melchor Díaz entró en contacto con este pueblo y describio en sus escritos las casas subterráneas que cavaban y que cubrian de tule o paja. Eusebio Kino encontró en sus visitas al río Colorado entre 1698 y 1702 a gente que creyó eran cucapá (Williams, 1983:100). Uno de los objetivos de este religioso era confirmar que la California era una península y no una isla como hasta el momento se había creído. Esto lo confirma en su viaje de 1702.

Por otro lado, el padre Francisco Garcés también incursionó en este territorio. Desde 1771 hasta 1776 censo y ubico las distintas comunidades aledañas al río Colorado. En las últimas páginas de su diario de 1776 describió que existran 3000 cucapá en el lado oeste del río. Al estar en un campamento cucapá expreso:

Durante mi estancia en este lugar arribaron muchos indios serranos a comer de los frutos que recogen los de estas rancherías, y que preguntaron si yo iba a visitar los padres de Baxa Califomia o aquellos de San Diego (Kelly,1977:7).

En 1779 Garcés y un puñado de soldados, establecieron una misión del lado oeste del río Colorado y un tanto al sur del río Gila, que fue destruida 


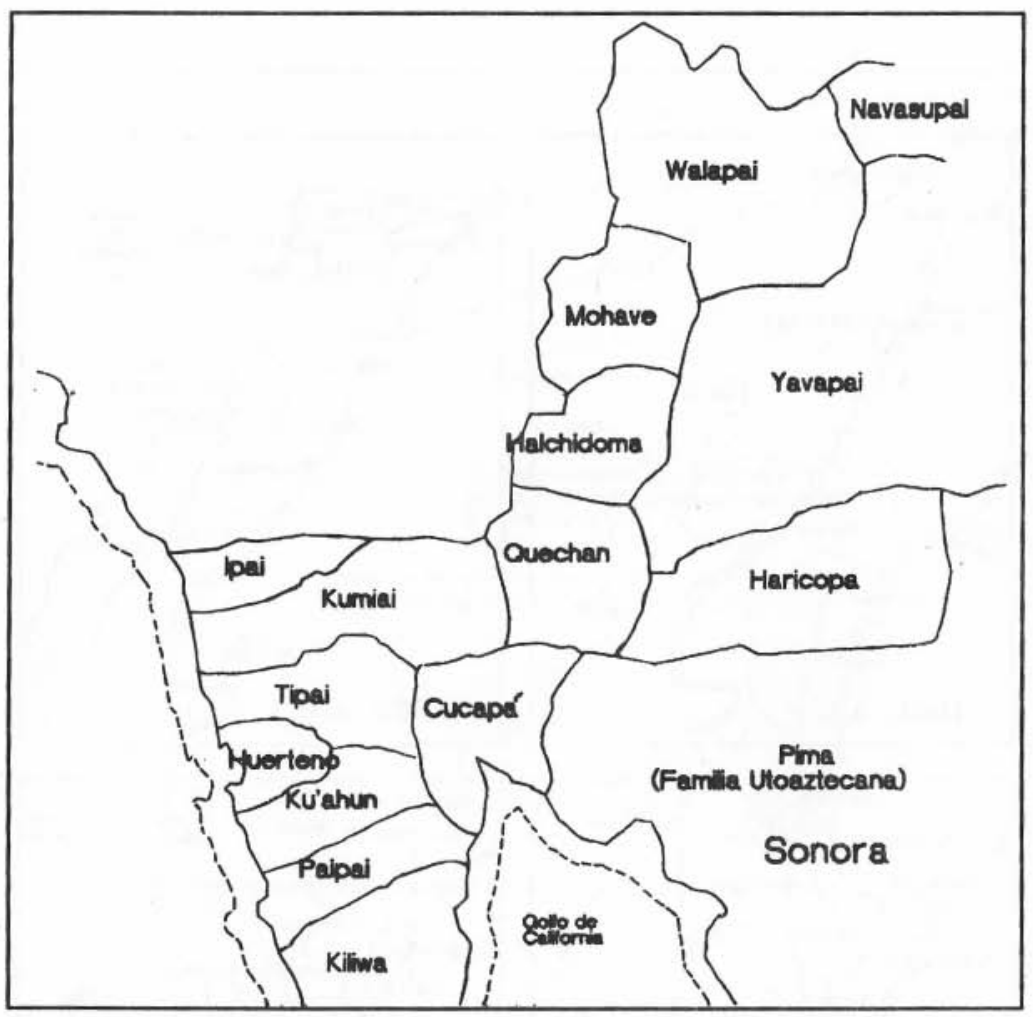

Figura 2.Distribución tentativa de las distintas lenguas yumanas en Baja California y suroeste de los Estados Unidos.

Fuente: Tomado de Don Laylander (1993:14) y modificado para este artículo.

por un ataque de indígenas yumanos en 1781, sólo a dos años de su fundación (Spicer, 1981:264). En este ataque murió Garcés. La política misional de la época tenía contemplado abarcar la región del río Colorado. Esa región se consideraba importante porque, a través de ella, se encontraba una ruta terrestre que comunicaba a la península con el resto del país. Sin embargo, durante este periodo, con la excepción de los exploradores como los que se mencionan y el intento de la misión franciscana en la región del río Colorado, las sociedades rivereñas presenciaron en general menor intromisión por parte de órdenes eclesiásticas que las sociedades al interior y en la costa penínsular, así como de la costa occidental de Alta California. 

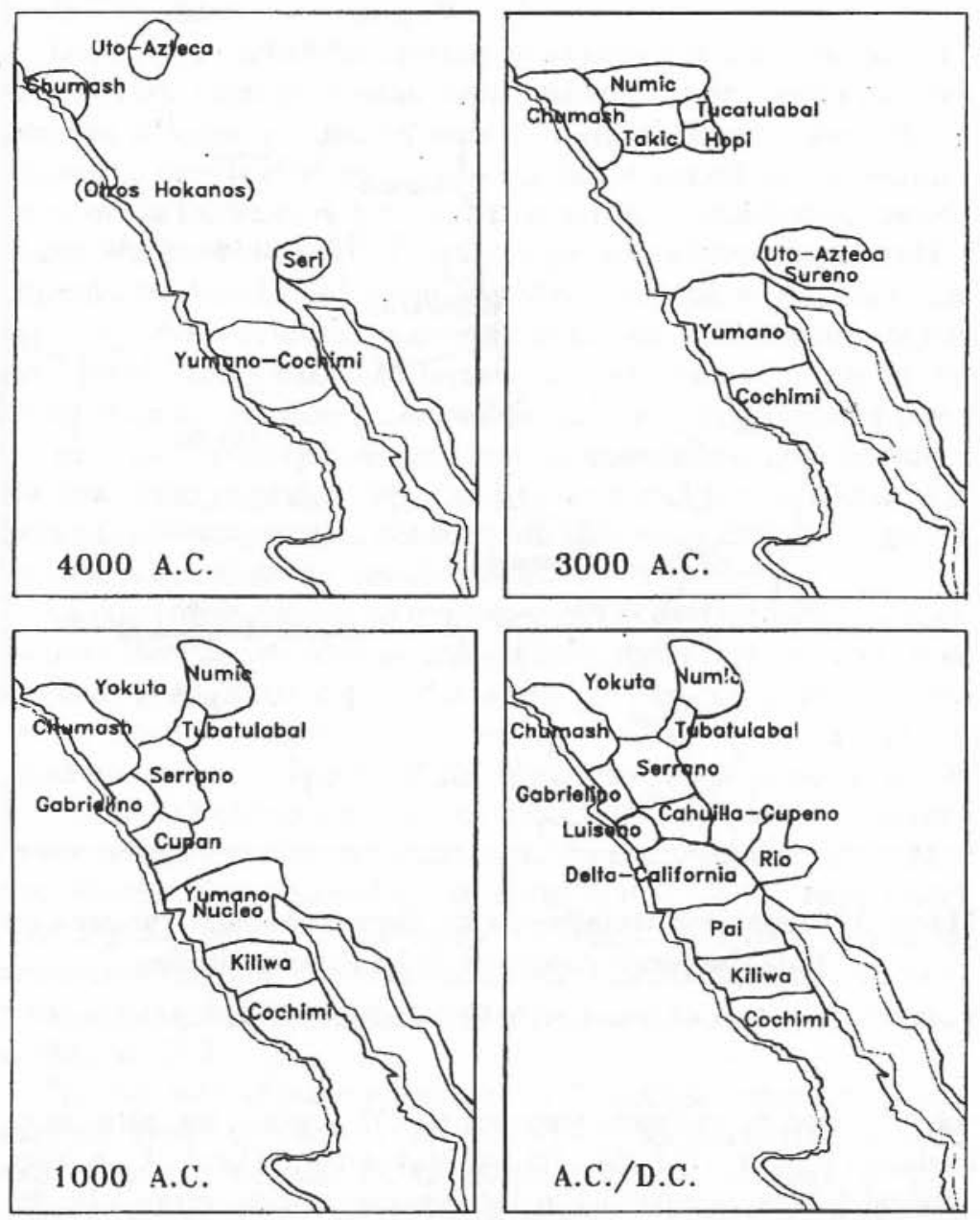

Figura 3. Mapa de etapas hipotéticas de la evolución lingüística prehistórica en el sur de California y porción norte de la península de Baja California.

Tomado de Laylander (1993). 


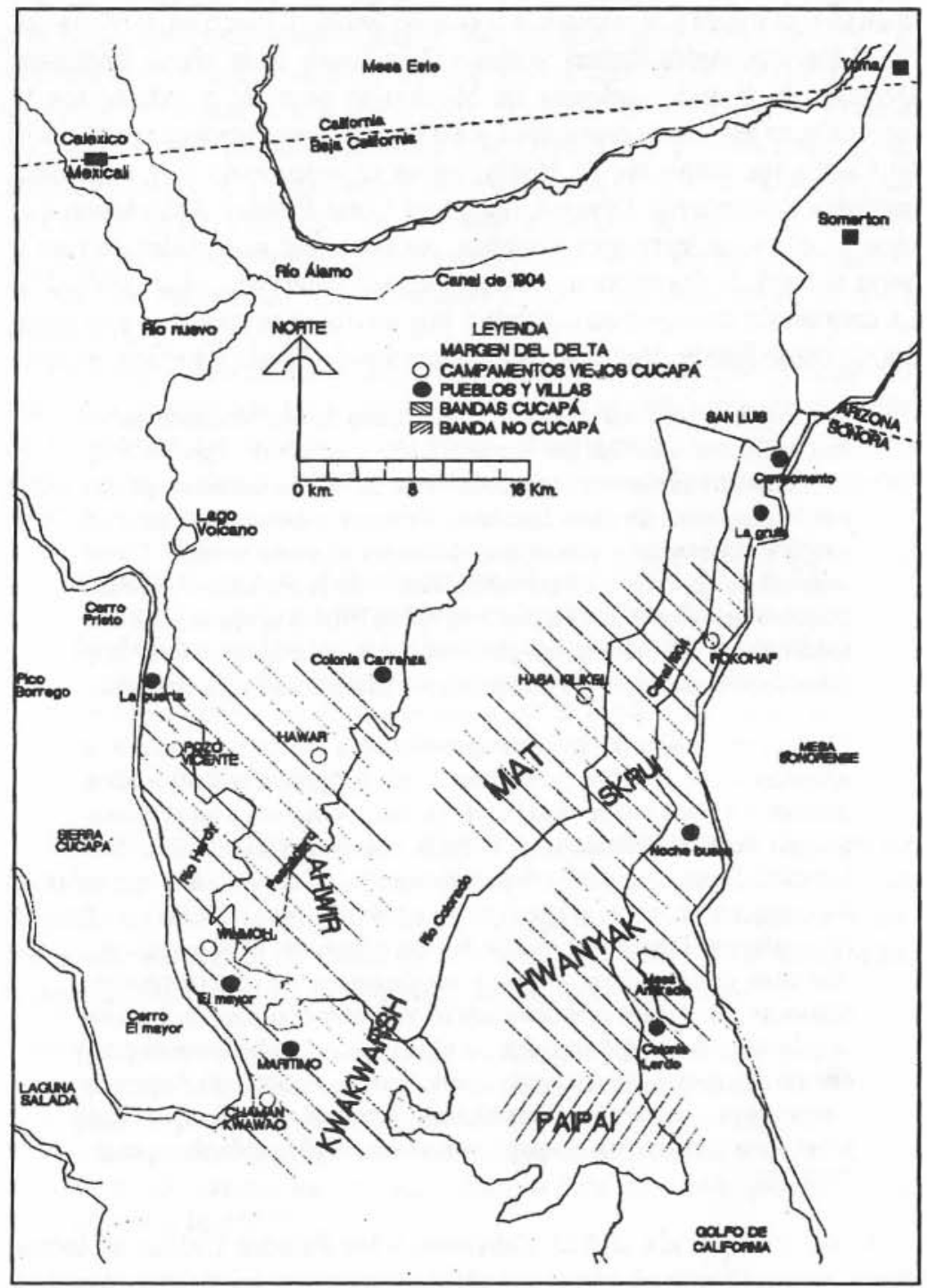

Figura 4. Ubicación de chumules cucapá en Baja California. Tomado de Kelly (1977:12). 
Quizá como lo menciona Anita Williams (1975:45), los cucapá escucharon el ingles por primera vez cuando ancló su barco en la ribera del ro el teniente ingles Robert William Hale Hardy de la Naval Británica. Después de la Independencia de México se permitió a extranjeros la incursion en territorios mexicanos y ast inician exploraciones por el golfo de California, como las de Hardy, quien representando a la compañía británica denominada General Pearl and Coral Fishery Association exploro el rí y los territorios aledaños, así como las vastedades de mar y tierra al sur de la desembocadura del Colorado (Martinez, et al., 1991:75). La cartografía conservo su nombre y hoy en día se le conoce a esta parte del río como Hardy. Veámos los comentarios de Hardy sobre los cucapa:

La respuesta que los indios nos han dado invariablemente es lo siguiente, nos enseñan por lo menos algún grado de algo no muy común: hay entre nosotros una sensación de no discusiones o peleas por la propiedad de otros hombres. Vivimos contentos y felices en grupo y respetamos y somos respetados por nuestros vecinos. Usted sabe que en guerra somos invencibles como en la paz somos corteses. Nuestras mujeres cuidan a nuestros hijos. Ellas son entrenadas con sentimientos de valor y no para venganza solamente cuando son insultadas olastimadas por un enemigo. Entre cristianos qué diferente!

Ellos beben fuego (un nombre que ellos dan a los espíritus), ellos apuestan a sus familias y asesinan a sus amigos, se roban a ellos mismos o a otros y bajo el signo de la cruz, persiguen a las personas que no pueden defenderse $y$ además engañan a los fuertes. Sus hombres viejos no son buenos para el consejo, así el fuego que toman los convierte en locos; al igual que en cualquier tribu indígena como ellos mismos dicen para hacerlos felices, solamente levantan discordias entre estos pueblos de paz; y sus capitanes son tiranos crueles. Entonces por qué los cristianos nos hacen sufrir con sólo venir hacia nosotros? nosotros estamos felices ahora y somos libres por mucho tiempo y vamos a seguir siendo libres. Nuestra nación está dispuesta a estar en paz con los hombres blancos, pero nuestros guerreros han jurado que ellos no van a sufrir viviendo entre ellos (Martínez, et al, 1991:75).

Al ser incorporada la Alta California a los Estados Unidos se incremento enormemente el número de inmigrantes que se dirigian hacia el oeste, cruzando el rfo Colorado y atravesando el lugar donde se encontraba una población indigena de bastante densidad. Por este motivo, el gobierno estadounidense establecio en 1852, de una forma permanente un batallon del ejército estadounidense en lo que llamaron el Fuerte de Yuma, un sitio ubicado muy cerca de la confluencia del río Gila y el róo Colorado, 
aproximadamente 100 kilometros al sur de la desembocadura del río Colorado. Este campamento militar fue, durante medio siglo, uno de los núcleos de población no-indígena que mayor influencia tuvo en las sociedades rivereñas y del delta. Los oficiales de los Estados Unidos encontraron que era más fácil entregar provisiones y municiones a las tropas ubicadas en Yuma a través del ró que por el desierto entre la costa de California y el Fuerte Yuma. De manera que el 3 de diciembre de 1852 el barco de vapor Tío Sam completó su primer viaje río arriba al campo Yuma. Los líderes cucapá El Colorado y José se encontraban en el navío (Williams, 1974:36-37).

Con la segunda mitad del siglo vino un incremento de barcos cargando todo tipo de artículos, tales como ropa, utensilios y otros bienes. Además de lo anterior, los dueños de los barcos contrataban a los cucapá como guías o pilotos, debido a sư conocimiento profundo de la red de cauces del río Colorado.

Durante la etapa de florecimiento de la navegación sobre el (río) Colorado los indígenas formaban parte de los equipos de las naves. A través de su asociación con los hombres blancos aprendieron muchas cosas que eran absorbidas en la cultura de su pueblo.... El arco y la flecha pasaron a ser de uso secundario al del rifle. Con las nuevas adquisiciones hubo una correspondiente negligencia de su propia cultura (Kniffen, 1981:56).

En 1873 el ingeniero Jacobo Blanco fue comisionado por el gobiemo mexicano para hacer un informe sobre el río Colorado, desde Yuma hasta el golfo de California, teniendo así la oportunidad de conocer a los indígenas del delta y de rendir un informe a la Secretaría de Desarrollo, Colonización, Industria y Comercio, donde destaco lo siguiente:

Los indios cucapá cortan leña que venden a la compañía de vapores del Colorado a 3 pesos la cuerda, que tiene por dimensiones $5 \times 4 \times 4$ pies. Se podrá tener una idea de la cantidad de leña que exporta y consumen los vapores, fijándose en los apuntes de la costera de campo, en donde indiqué los diferentes sitios de leña por donde pasaban (Álvarez, Ila:1977).

En la zona del delta existía el carrizo con gran densidad y además grandes bosques de álamo negro (Populus fremontol Wats) y de sauce (Salix goodinggil Ball) que son árboles de rápido crecimiento y que se adaptan bien a los cambios de curso de los canales o vertientes del río. Las características ecológicas fueron un elemento central en la historia de este grupo. Una publicación de Southworth, en 1899, nos informa de tierras 
fértiles, espesas arboledas de sauces, álamos, animales para la cacería como berrendos, venados y chivos salvajes, codomices, patos, peces como el barbo y el salmón, cáñamo silvestre y mezquites. En cuanto a recursos minerales reporta que en la sierra Cucapá existen yacimientos de oro y depósitos de azogue, cobre y azufre (Martínez et al., 1991:128).

A fines del siglo pasado el desarrollo agrícola es iniciado de forma explosiva por compañías cuya tenencia de la tierra se obtuvo por medio de las leyes de colonización de Lerdo de Tejada y Manuel González. Esto tuvo como resultado el despojo de tierras de los indígenas. En el caso de los cucapá, aunque es problable que sus ancestros hayan habitado durante miles de años en el valle de Mexicali y en la región del delta, no tenían documentos de propiedad por lo que los intrusos fácilmente se apropiaron de sus tierras. En 1883 se promulgó la Ley de deslinde y colonización de terrenos baldíos. Unos años antes, en 1878, Guillermo Andrade, empresario mexicano, logró una concesión de tierras en la zona de Mexicali y del delta del río Colorado, afectando a los cucapá y a los kamiai del desierto (Sánchez Ogaz, 1986:8).

Una vez promulgada la Ley de colonización, en 1888, Andrade firmó un nuevo contrato con el gobierno de Porfirio Díaz y obtuvo 302231 hectáreas en el valle de Mexicali, entre las cuales se encontraba el territorio que entonces ocupaban los cucapá. En el caso de Andrade estos terrenos le fueron cedidos con la condición de que dotara a 70 familias cucapá de 10 hectáreas a cada una, condición que nunca cumplió y a consecuencia de lo cual los cucapá se refugiaron en la actual zona de El Mayor. Posteriormente, en 1897, Andrade firmó con el gobierno un nuevo contrato en el cual se comprometía a dotar a los cucapá de 5000 hectáreas si se establecían como colonos; sin embargo, este contrato tampoco lo cumplió. Más adelante este negociante vendió la mayor parte de sus tierras a la Colorado River Land Company, que llego a tener posesión de terrenos hasta el río Hardy (zona cucapa). La mencionada compañía mantuvo en propiedad el valle de Mexicali durante 30 años, mientras que los cucapá emigraron a otras regiones como a Somerton, California, o permanecieron y trabajaron como peones para la mencionada compañía (Sánchez Ogaz, 1986:8).

En esa época de grandes programas de desarrollo, diferentes comisiones recorrían la región y en sus informes describen a los cucapá y sus condiciones de vida. En uno de estos documentos el jefe político Agustín Sanginés, el primero de febrero de 1896 solicita a la Secretaría de Gobernación que se tomen medidas para evitar que los indios de las comunidades de los Estados Unidos penetren a territorio nacional y en él hace una interesante referencia a la forma de vida de los cucapá. 
Por vía de informe me permito manifestar a Usted que respecto al carácter y modo de ser de los citados indígenas, tengo formada la opinión de que son quietos y pacíficos, incapaces de intentar cosa alguna contra el orden público, son obedientes y sumisos a las autoridades y pueden muy bien calificarse de seres inofensivos cuya existencia, aunque no produce beneficios a la sociedad, tampoco puede inquietarla de manera alguna.

Con el fin de dar a conocer mejor a estos individuos inserto enseguida un informe rendido últimamente por el Juez de Paz de Algodones, en el cual se expresan, aunque incorrectamente respecto a la forma, de una manera minuciosa y clara, las principales costumbres y rasgos característicos de tales indígenas. El mencionado informe dice lo siguiente:

Le escribo en este de mi cargo el oficio No. 2 girado por la sección primera de esa Secretaría, con fecha 4 del actual, en el que se sirve pedirme un informe detallado acerca de las costumbres y conducta que observan los indígenas cucapas...me permito manifestar a Usted que los expresados indios observan buena conducta, no son inclinados al robo...se dedican a sembrar pequeñas porciones de terreno. Para esto...se ponen a trabajar, haciendo zanjas para traer el agua de los arroyos, que se forman por las crecientes del río Colorado o del mismo río cuando las crecientes tardan en presentarse con el fin de regar las tierras en las cuales siembran maíz el que llaman en su idioma fediche, frijol colorado que nombran, si es de la clase chica...y si es grande, maricuata, hay también un frijol chico amarillo, que nombran llariman, y el blanco...siembran también trigo que nombran hajache cuando levantaban su cosecha, se convidan de una ranchería a la otra, y así viven hasta que acaban con el producto, cuando pasan a otro lugar y hacen lo mismo ayudándose así unos a otros. Los indios por lo general son flojos y la mayor parte del trabajo es hecho por las mujeres. Cuando no tienen que comer los más inteligentes se ocupan de cazar conejos. Para esto usaron flechas y ocupan también en sacar pescado, al que nombran chmoguil; comen los caballos, mulas y burros que mueren, hacen pinole, de la fruta del mezquite...del palo fierro, de chamizo de cachanilla y otras yerbas, algunos pasan el tiempo en las rancherías de los vecinos, jugando a las barajas, observan también sus días festivos, jugando carreras de caballos, de burros y a pie...Acostumbran quemar a los muertos y aunque yo he querido en repetidas ocasiones hacerlos desistir de esta costumbre, no he podido conseguirlo. Es todo lo que tengo que informar a esa superioridad.

Para concluir me tomo la libertad de agrupar que, según informes fidedignos, desde tiempo inmemorial existen en aquella región grupos bastante numerosos de las tribus cucapá, yuma y dieguenos, los cuales 
se han reducido de manera asombrosa; que muchos de esos indígenas atraídos por las dádivas del gobiemo norteamericano abandonan las reservas...sería conveniente, salvo el mejor parecer de esa superioridad, que dejando ilesos los derechos del $\mathrm{Sr}$. Andrade, se les asigne a cada una de las tribus referidas un lote de terreno suficiente para cubrir sus pequeñas necesidades...(Documento del Archivo del Centro de Investigaciones Históricas, [CIH], 1986).

El investigador William Kelly informa que en 1900 y 1910 , casi todos los cucapá wi awir se trasladaron a las cercanías de Mexicali, o a lo largo del ferrocarril inter-californiano que empezaba en San Diego, California y terminaba en Yuma, Arizona. Otras familias, principalmente del grupo hwanyak, emigraron a Arizona, en las cercanías de la población de Somerton, en tanto que otras se reunieron en unas tierras que se encuentran al sur de San Luis Río Colorado, Sonora, uniéndose al grupo de los mat skrui. Los dos últimos movimientos de población dieron inicio al establecimiento de comumidades cucapá que perdurarian hasta nuestros días. De hecho, en 1917 el gobierno estadounidense otorgo una pequeña reservación al grupo hwanyak, establecida en la zona de Somerton, Arizona, la que quedó bajo la jurisdicción de la Agencia de Asuntos Indígenas en Yuma, Arizona (Kelly, 1977:13).

En 1914 Andrade vendio su emporio a la companía que se volvio virtual dueña de todo el valle de Mexicali, David Golbaum en 1918, cumpliendo con una solicitud del gobierno referente a las comunidades indígenas (Golbaum, 1984:26) hace mención a las comunidades del valle de Mexicali y de la región del delta del río Colorado de la siguiente forma;

...los pocos cucapás que habitaban la cuenca de los ríos Colorado y Hardy son los más apreciados como trabajadores en los trabajos de los canales de irrigación que abundan en esa región, por estar aclimatados y en los meses de más calor no resultan afectados (Golbaum, 1984:26).

En 1937 se dotó a los cucapá de 2340 ha, que fueron otorgadas por resolución presidencial el 5 de mayo de ese mismo año como ejido Cucapá Indígena. Al poco tiempo, debido a la intervención de organismos estatales y a las formas novedosas que pretendían integrar al indígena a la forma de producción dominante, los cucapá olvidaron su estrategia colectiva de trabajo y perdieron sus tierras ejidales. La tierra concedida pasó a manos de mexicanos no indígenas (Sánchez Ogaz, 1986:9).

Muchos ejidatarios indígenas fueron engañados, obligados a poner su huella en documentos que no entendían, renunciando a sus derechos agrarios, o bien se les acusaba de haber abandonado el cultivo personal de 
sus parcelas. Sólo hubo un caso de defensa de derechos agrarios entre la gente despojada de aquel ejido. En 1943, Francisco Hernández, cucapá, envió un telegrama al jefe del Departamento Agrario donde "reconociendo sus derechos..." se analizaba su caso. Sin embargo, el despojo se realiz6 porque en el Diario oficial de la federación del 21 de julio de 1960, definitivamente, el Departamiento de Asuntos Agrarios y Colonización, le privó de sus derechos y junto con él, a otros 21 miembros del ejido Cucapá Indígena, otorgándose a otros tantos mexicanos quienes desde 20 años antes ya las ocupaban (Sánchez Ogaz, 1991).

Como consecuencia de estos abusos ellos perdieron los predios que durante siglos cultivaron, obligándoles a salir de esos lugares cercanos al río y emigrar hacia Somerton, en Estados Unidos o bien al sur de San Luis Río Colorado, en Sonora. Los que se quedaron, vivieron dispersos a lo largo de las corrientes de agua cercanas al río Hardy, entre el kilómetro 60 hasta el 80 de la carretera a San Felipe. Sin tierras, los cucapá tuvieron que dedicarse a diversas actividades, tales como pizcadores de algodón, obreros, empleados en campos turísticos aledaños y la pesca. Actualmente en ese tramo residen alrededor de 12 familias de origen cucapá.

Los cucapá siguieron luchando. Solicitaron tierras aledañas al río Hardy e insistieron durante años por una resolución favorable. Por fin, en 1973 se publico en el Diario oficial de la federación del 29 de junio, la resolución presidencial que se firmó en agosto del mismo año y fue ejecutada hasta el 7 de julio de 1976. Con este trámite se les concedieron 143053 hectáreas a 42 jefes de familia cucapá (Sánchez Ogaz, 1991:10).

Sólo que no les dieron las tierras aledañas al Río Hardy como pedían y si bien fueron dotados por RTBC(Reconocimiento y Titulación de Bienes Comunales) sólo les reconocían 143,053 hectáreas de piedra, arena y agua pues la resolución presidencial ampara la Sierra Cucapá y la Laguna Salada, esta área forma la comunidad El Mayor Indígena (Sánchez Ogaz, 1991:10).

Según la profesora Yolanda Sánchez Ogaz, quien entrevistó al Sr. Pedro Pérez, campesino del ejido Michoacán de Ocampo, existió un líder cucapá que organizó y representó a la comunidad durante la reforma agraria. Este personaje se llamaba Enrique Osben. Represento a los cucapá en el primer Congreso Indigenista Internacional realizado en Pátzcuaro, Michoacán, en 1940 durante el gobierno del presidente Cárdenas. Entonces gobernaba el territorio de Baja California el coronel Rodolfo Sánchez Taboada, gran amigo de los campesinos, quienes visitaban el palacio de gobierno con entera libertad y eran atendidos por el gobernador, como lo investiga y registra Sánchez (Sánchez Ogaz, 1991:10). El sr. Osben asistió 
en una ocasión en la que varios campesinos acompañaron al diputado federal Hipolito Rentería. Según recordó el Sr. Pedro Pérez al ser entrevistado dijo:

Estábamos en aquella oficina del gobernador, tan grandota, íbamos con don Hipólito y también iba el jefe de los indios, Enrique Osben se llamaba, era un hombrote muy alto, siempre bien vestido y con las botas muy brillosas. Cuando le tocó hablar, le dijo al gobernador: hágase para allá, y le señaló la ventana. Sánchez Taboada se acerco, y Osben le volvió a decir: hágase para allá y le contestó el indio. Esto nos están haciendo a los cucapá, nos han ido quitando las tierras y nos van empujando al desierto...

Costó mucho esfuerzo por parte de los cucapá lograr sus derechos agrarios y esto se puede observar en las numerosas peticiones y escritos dirigidos a las autoridades. En uno de estos documentos Onésimo González dice:

Es consenso y hecho histórico incotrovertible que desde una época inmemorial los chapai habitaban la región, desde la junta de los ríos Gila y Colorado, conocido por nosotros como Ja juil cuauat, la zona del denominado delta y parte de la costa peninsular hasta Wi-ñnur (Cueva de las Pintas)...(Sánchez Ogaz, 1991).

Desde 1976 a los cucapá se les otorgó una gran extensión de tierra donde la agricultura no es posible por falta de agua y suelos fértiles; sin embargo estas tierras poseen otras riquezas, por ejemplo, minerales como el yeso, cal, grafito, azufre, oro y cristal de roca y de materiales pétreos.

En 1975 la Secretaría de Educación Pública construyó una escuela primaria èn la zona cucapá. Según la profesora Leticia Alvarado, a quién le tocó iniciar la escuela, la inscripción de los niños que entonces vivían en el borde del río Hardy y la carretera a San Felipe, en un tiempo llegó a ser hasta de 60 alumnos de edades entre 7 y los 16 años. La escuela denominada Alfonso Caso funcionó durante cinco años al cabo de los cuales se presentaron crecientes del río Colorado y la escuela tuvo que ser abandonada. El líder cucapá Onésimo González logró que se les dotara un terreno federal entre el río y la carretera para construir su nueva escuela. Allí se construyó un cuarto provisional que se utilizó como aula hasta 1981, cuando se construyó la escuela actual. Expresa la profra. Alvarado que el principal problema que afronta la educación en la comunidad es que se carece de un programa bilingüe y bicultural, como resultado de esto cada día menos niños conocen y hablan su lengua y en cuanto a su cultura (como se conoce etnográficamente), prácticamente ha desaparecido, pues sus 
principales manifestaciones como la danza, la música, tradiciones y costumbres, ya no se practican (Sánchez Ogaz, 1991).

\section{TERRITORIO, MEDIO AMBIENTE Y REPRODUCCIÓN SOCIAL}

Según las referencias bibliográficas que hemos visto, los cucapá vivieron en la región sureña del río Colorado ocupando las tierras de acuerdo al curso del agua o a la hidrografía. Se establecieron en ambas márgenes del río y utilizaron hacia el oeste el espacio entre las orillas del río Hardy y la base de la sierra Cucapá. Esta división geográfica no implicaba divisiones sociales ni culturales.

El bajo delta del río Colorado está situado en la parte norte del desierto de San Felipe en una zona excepcional, debido a que las inundaciones anuales del río han depositado aluvión a través de miles de años, provocando que la zona sea un lugar lleno de vegetación y animales. Basta leer lo que narra don Juan García Aldama (q.e.p.d):

(Cuando estaba chiquillo no hacía nada) puro jugar. Ub! más antes juego mucho. Más antes como quiera andan los chamacos. Comer mucha comida... palo fierro...biznag(a), tule, papa hay muchos también...(Antes) aquí había mucho kuak gentil (vacas salvages). (Además) había borrego llamado mu. Hay muchas clases de pescado...: (Cuando estaba chamaco yo pescaba). (Andabamos en) ko. pap (balsas que) habían de tule. (Eran) muy grandes... En eso iban pa allá por trigo cucapá, ñipa cucapá.

(Cuando yo estaba chiquitito) sembrábamos... puro elote, calabaza, todo...frijol yuri mun. Sembrábamos cuando viene mucha agua así (y) cuando baja el agua ahí siembra toda la gente. No se riega. Con la brisa nomás, con eso sak, brisa... (información personal Juan García Aldama, 1985).

En la actualidad el control del río Colorado y sus vertientes ha transformado las condiciones físico-bióticas de la región. El territorio cucapá es cerril escarpado con abanicos aluviales que se encuentran surcados por cauces con escurrimientos esporádicos. Los suelos son arenosos pedregosos, por lo que algunos aprovechan el material pétreo para la construcción. La agricultura en el territorio es prácticamente inexistente debido a que ha disminuido dramáticamente el flujo de agua en el lecho del río Hardy. La precipitación pluvial, que es invernal de un promedio de 70 milímetros no permite siembras de temporal. La agricultura, que fue una forma de producción económica importante para los cucapá en el pasado, dejo de serlo. 
Los cultivos antes de que llegaran los no indígenas dependían totalmente de las inundaciones del río, que se presentaban en mayo y se retiraban en el verano. Había años con inundaciones en febrero o en el otoño (Martínez et al., 1991:133). La unidad de producción era la familia y tanto la tierra como sus recursos se consideraban propiedad colectiva.

La temperatura es de un promedio de 25 grados centígrados. Hoy en día la flora y la fauna aledañas a la comunidad son propias del desierto. Se encuentra una flora con cactáceas y xirófilas y los animales más comunes son los coyotes, codornices, faisanes, patos, mapaches, lagartijas, serpientes y gato montés. En la actualidad los cucapá se dedican a una serie de trabajos dentro y fuera de la comunidad. (ver cuadro 1 ).

La pesca siempre fue una forma de procurarse el sustento entre los cucapá. Antes pescaban en el río Colorado y en sus vertientes como el río Hardy. Existían cienegas y posiblemente lagunas como la que se formo hace más de una década en un valle desértico; parte del desierto de El Colorado. Esta última denomida laguna Salada quedó incluida en las tierras cucapá y a finales de la década de 1970 se llenó con los excedentes del agua del río poblándose sus aguas con diferentes especies como liza, bocón, bagre y carpa, las que aprovecharon los cucapá. El $90 \%$ de los jefes de familia cucapá y algunas mujeres se dedicaban a la pesca, pero finalmente por la falta de excedentes del río Colorado, la laguna se secó. Actualmente siguen pescando en un lugar en la boca del golfo que denominan La Bocana.

S6́lo unas cuantas personas siguen pescando, aquellos que tienen los medios para hacer el viaje a aproximadamente 80 kilometros hasta la boca del río Colorado, jalando un barco y su motor, además âel equipo para pescar, ya sean redes o cañas. Los que lo logran pescan una variedad de peces entre los que destaca la curvina que venden a 4.5 pesos el kilo (Información proporcionada por Inocencia González, indígena cucapá).

La actividad artesanal es muy importante para algunas personas de la comunidad. Durante los últimos años ha aumentado el número de artesanas que participan en esta forma de trabajo obteniendo así recursos que ingresan a la economía familiar. Los trabajos que realizan son los collares de chaquira; una pieza ornamental que inician a elaborar después del contacto con los viajeros que incursionan por el río Colorado y que mediante el trueque por productos naturales con esta sociedad, les proporcionan las cuentas de chaquira que ellos aprenden a utilizar para elaborar los collares. Con el tiempo evoluciona este trabajo para incluir otros elementos que son comunes en los ornamentos de este tipo en el suroeste de los Estados Unidos y noroeste de México como los cintos, aretes y prendedores. Dos artesanas importantes son Inocencia y Carolina 
González. Ambas reaprendieron la técnica para elaborar objetos de chaquira de un cucapá que hemos mencionado en este trabajo llamado Juan García Aldama, quien nació en la penúltima o última década del siglo pasado y que tuvo influencia sobre ellas. “...Don Juan García Aldama me dio la idea de cómo elaborar los collares de chaquira y así empecé a enseñar a mis ahijadas y cuñadas a trabajar la chaquira" (Información proporcionada por Inocencia González, 1996).

Ahora existen aproximadamente 22 artesanos (16 mujeres y 6 hombres) orgnizados en un grupo artesanal que coordina Antonia Torres. Inocencia González ha ganado premios nacionales en varias ocasiones por la belleza de su trabajo. La Sra. Pascuala Saiz, quien pertenece a la comunidad, recuerda que:

cuando era chiquita mi papá tenía muchas vacas, yo ciudaba las vacas. Mi tía Mariana también tenía vacas, ella tenía muchas vacas. A su casa llegaba la gente a comprar y vender. La gente decía, vamos con Mariana, porque allí había una ramada muy grande donde se juntaban los vaqueros. Por eso a ese lugar se le llama Colonia Mariana.

Mi papá también sembraba, hizo una ramada alta y arriba ponía las calabazas, el maíz, frijol y las sandías, para que los animales no se las comieran. siempre había comida (Entrevista de Pascuala Sainz por Yolanda Sánchez, en Sánchez Ogaz, 1991).

\section{CONCLUSIONES}

Son dramáticos los cambios que sufrieron los cucapá abatidos por los distintos procesos que causaron el contacto con los no indios, el cambio de su contexto natural y cultural del medio ambiente y la disminución de alternativas para sobrevivir. En la sociedad de hoy su marginación es evidente. El idioma, un elemento cultural de suma importancia sólo es hablado por unas cuantas personas mayores y pocos jovenes lo comprenden. Aunque no ocurre únicamente con los cucapá sino también podemos observarlo entre las demás etnias nativas de estas tierras, es verdaderamente poco el tiempo que le queda de vida a esta lengua. Solo viven 212 personas en la comunidad:

...en un documento del 23 de abril de 1870, Marto Cruz, general capitán de las tribus del delta, yumas, dieguinos y cucapás, informó que en los terrenos del Colorado vivían más de 5000 indígenas. Hacia 1872, Manuel Clemente Rojo, consideró que la región del río Colorado estaba poblado por 3500 indios cucapá, dieguinos y yumas. (Martínez et al., 1991). 
CUADRO 1. Lista de población económicamente activa, cucapá o mestizos, del poblado El Mayor.

\begin{tabular}{|c|c|c|c|}
\hline Nombre & $\begin{array}{c}\text { Edad } \\
\text { aproximada }\end{array}$ & Ocupación & Sitio de trabajo \\
\hline Matías Saenz Portillo & 60 af́os & Reconstrucción de caminos & caminos de la laguna Salada \\
\hline José Alejandro Saenz Glez. & 20 & Reconstrucción de caminos & caminos de la laguna Salada \\
\hline Francisco Cecefia Diaz & 21 & Reconstrucción de caminos & caminos de la laguna Salada \\
\hline Susana Saenz Glez. & 22 & Reconstrucción de caminos & caminos de la laguna Salada \\
\hline Juana González Saenz & 50 & Reconstrucción de caminos & caminos de la laguna Salada \\
\hline Genaro Torres González & 36 & Albafíil & Campo 3-B \\
\hline Alejandro Torres García & 20 & Pescador & Las Cortinas \\
\hline Gabriel Antonio Torres García & 22 & Jornalero & El Caimán \\
\hline Teodoro Sández González & 37 & Albaf̛̣il & Campo Mosqueda \\
\hline Rosa María Saenz & 34 & Reconstrucción de caminos & caminos de la laguna Salada \\
\hline Antonio Flores & 60 & Reconstrucción de caminos & caminos de la laguna Salada \\
\hline Manuel Antonio Torres Rdez. & 70 & Reconstrucción de caminos & caminos de la laguna Salada \\
\hline Antonio laguna Rdez & 65 & Reconstrucción de caminos & caminos de la laguna Salada \\
\hline Rómulo Méndez & 45 & Reconstrucción de caminos & caminos de la laguna Salada \\
\hline Eva García & 41 & Reconstrucción de caminos & caminos de la laguna Salada \\
\hline Lorenzo Saenz & 19 & Pescador & Las Cortinas \\
\hline Fernando Carrillo & 16 & Pescador & Las Cortinas \\
\hline Onésimo González & 70 & Pescador & Las Cortinas \\
\hline Armando Carrillo Saenz & 17 & Vigilante de casa & Cerro El Mayor \\
\hline
\end{tabular}




$\begin{array}{llll}\text { Francisco Javier González } & 35 & \text { Ayudante de taller } & \text { Comunidad Cucapá } \\ \text { Daniel Rapp Saenz } & 41 & \text { Dueńo de taller } & \text { Comunidad Cucapá } \\ \text { Perla Torres González } & 21 & \text { Artesana } & \text { Comunidad Cucapá } \\ \text { Rosenda Domínguez Saenz } & 60 & \text { Artesana } & \text { Comunidad Cucapá } \\ \text { Rosa Méndez Domíngez } & 23 & \text { Artesana } & \text { Comunidad Cucapá } \\ \text { Inocencia González } & 60 & \text { Artesana } & \text { Comunidad Cucapá } \\ \text { Juana Torres González } & 38 & \text { Artesana/ auxiliar de Medicina } & \text { Comunidad Cucapá } \\ \text { Reyna Muro Muńoz } & 34 & \text { Artesana } & \text { Comunidad Cucapá } \\ \text { Martín Rodríguez } & 26 & \text { Operador/artesano } & \text { Comunidad Cucapá } \\ \text { Carlos Luna Coronado } & 23 & \text { Reconstrucción de caminos } & \text { caminos de la laguna Salada } \\ \text { Isabel laguna Rodríguez } & 22 & \text { Artesana/recons. de caminos } & \text { Comunidad Cucapá/Salada } \\ \text { Prisciliano González Atvarado } & 22 & \text { Albañil/Artesano } & \text { Campo } \\ \text { Barbara González } & 70 & \text { Hogar } & \text { Comunidad Cucapá } \\ \text { María Carrillo Olivares } & 29 & \text { Artesana/reconsı de caminos } & \text { Comunidad Cucapá } \\ \text { Javier Cecef́a Díaz } & 19 & \text { Artesana/recons. de caminos } & \text { Comunidad Cucapá/Salada } \\ \text { Carlos Gonźlez } & 68 & \text { Vigilante de campo Turístico } & \text { Comunidad Cucapá } \\ \text { Jesús Gabriel laguna } & 26 & \text { Reconstrucción de caminos } & \text { caminos de la laguna Salada } \\ \text { María Isabel González Portillo } & 25 & \text { Artesana } & \text { Comunidad Cucapá } \\ \text { Antonia Torres González } & 34 & \text { Artesana } & \text { Comunidad Cucapá }\end{array}$

Fuente: Información proporcionada por Antonia Torres González, indígena cucapá. 
La unidad de producción sigue siendo la familia y el Reconocimiento y Titulación por Bienes Comunales los hace dueños en forma colectiva de una gran porción de territorio. Sin embargo, la explotacion agrícola tradicional es imposible de hacerse por las razones que ya hemos visto. La flora y la fauna que hace menos de 20 años todavía podía ser apreciada en la región general, dejo de exiștir y con ello otras alternativas para los indígenas. Podrían sembrar calabaza, frijol y maíz como lo hacían hace poco más de 20 años, pero sin agua o con la calidad del agua a la que tienen accesso no pueden producir cosecha alguna. "Más antes (las mujeres tenían el cabello) largo y trenza bonita! Toda la gente hacía chaquira...(Lo hacían) pues dijo Dios hacen así, el Dios le dice mire y todo eso... " (Información proporcionada por Juan García Aldama, 1985).

Los indígenas cucapá son los pioneros del territorio que hoy en día ocupa la ciudad de Mexicali y su valle. Continúa siendo urgente hacer programas que les permita subsistir mejor, aprendiendo a utilizar sin engaños los recursos que tienen en su territorio. Es también vital apoyarlos con estudios y programas para intentar juntos refuncionalizar sus razgos culturales ancestrales; su patrimonio cultural.

La globalización hoy en día pretende en el fondo unir a las sociedades bajo el gran manto del consumismo; integrarlos, hacerlos que se vuelvan indistinguibles, amantes de los mismos sabores, ropa, cine, música, colores, juguetes. Al ver esto no se puede mas que imaginar un día a un mundo que perdiera la rica variedad de enfoques culturales, de formas de adaptarse a diferentes entornos naturales y sociales.

Vemos que con gran velocidad van cayando las voces de sociedades que significaron mucho en el tiempo, los calla la indiferencia, la codicia y el egoismo. Vamos perdiendo respeto por la diversidad humana y el valor de cada persona (Barnet et al., 1994:430) Si deseamos heredar un mundo rico en la variedad y calidad humana, le debemos apoyo a los grupos humanos orillados a la extinción desde hace cientos de años y aún en nuestros días. 


\section{BIBLIOGRAFIA}

ÁLVAREZ, Ila. 1977. "Viaje de un cartógrafo desde San Diego a Yuma por Tierra, y en vapor por el río hasta el mar de Cortés. Doc. Núm. 35." Introducción y notas de Ila Álvarez, texto y mapa de Jacobo Blanco. Documento inédito.

BARNET, Richard y John Cavanagh. 1994. Global Dreams. Imperial Corporations and the New World Orders. A Touchstone Book.

BENDÍMEZ, Julia. 1987. "Antecedentes históricos de los indígenas de Baja California”. Estudios Fronterizos. Vol. v, núm.14, Instituto de Investigaciones Sociales, UABC.

- 1991. "La Prehistoria en el Noreste de Baja California". En Mexicali: Una Historia Ed. Jorge Martínez, Tomo I, Universidad Autónoma de Baja California.

GOLBAUM, David. 1984. "Respecto a las comunidades indígenas que pueblan el Distrito Norte de la Baja California". Calafia, vol. v, núm. 3, Instituto de Geografía e Historia, Universidad Autónoma de Baja California.

GIFFORD, Edward. 1933. "The Cocopa", University of California Publications in American Achaeology and Ethnology, núm. 31.

KELLY, William. 1977. Cocopa Ethnography. Anthropological Papers of The University of Arizona.

KNIFFEN, B. 1981. "The Primitive Cultural Landscape of The Colorado Delta". University of California Publications in Geography, núm.5.

LAYLANDER, Don. 1985. "Some Linguistic Aproaches to Southern California Prehistory". San Diego State University Cultural. Resource Management Casual Papers, vol. 2, núm. 1.

- 1993. "Enfoques lingüísticos sobre la prehistoria del sur de California". Estudios Fronterizos, núm. 31-32, mayo-agosto/septiembre-diciembre, Instituto de Investigaciones Sociales, Universidad Autónoma de Baja California.

MARTÍNEZ, Jorge et al. 1991. "Del trazado de la línea intemacional a la colonización del bajo delta del Colorado". En: Mexicali: Una Historia. Editor Jorge Martínez, Instituto de Investigaciones Históricas de la Universidad Autónoma de Baja California.

SÁNCHEZ, Ogaz Yolanda. 1986. Documento del Archivo del Centro Investigaciones Históricas ( $\mathrm{CIH})$.

SPICER, Edward. 1981. Cycles of Conquest, University of Arizona Press, Tucson, Arizona. 